\title{
MYOCARDIAL REVASCULARISATION IN PATIENTS WITH SEVERE LEFT VENTRICULAR DYSFUNCTION. EARLY AND MIDTERM RESULTS
}

\author{
Jiři Škorpil*, Radim Brát, Bohumil Dočekal, Oldřich Motyka
}

Department of Cardiac Surgery, University Hospital Ostrava, Czech Republic, * jiri.skorpil@seznam.cz

Received: April 30, 2004; Accepted: June 18, 2004

Keywords: Myocardial revascularisation/Severe left ventricular dysfunction

Presented in part at $15^{\text {th }}$ Biennial Congress of Association of Thoracic and Cardiovascular Surgeons of Asia, Mumbai, India, December 6-9, 2001 and at 10 years Jubilee symposium of Department of Cardiac Surgery, Ostrava University Hospital, Czech Republic, October 24, 2003.

\begin{abstract}
Aims: This retrospective study evaluates early and midterm results in patients with severe left ventricular dysfunction.

Technique: Ninety-seven consecutive patients with coronary artery disease and ejection fraction of left ventricle (LVEF) less or equal to $25 \%$ underwent elective coronary artery bypass graft procedure between September 1998 and December 2001. Mean age at operation was $66(47-86)$ years. The main symptoms were angina class III-IV Canadian Cardiovascular Society (CCS) in 78 patients ( $80 \%$ ) and dyspnoea class III-IV New York Heart Association (NYHA) in 43 patients (44\%). The major indications for surgery were severe angina, dyspnoea in 90 patients (93\%). Cardiac index (CI), echocardiography (ECHO), planimetry, end-diastolic pressure of left ventricle (LVEDP), end-diastolic diameter of left ventricle (LVEDd) were used to access left ventricular function preoperatively. ECHO was also used to access left ventricular function postoperatively.

Results: Early postoperative (30 days) mortality was $4.1 \%$. Complications had 25 patients ( $26 \%$ ) postoperatively. Two years survival was $95.7 \%$. Class III-IV CCS and/or NYHA had 17 patients (17.5\%) two years after surgery. LVEF (assessed by ECHO) improved from $23.1 \%$ preoperatively to $36.0 \%$ postoperatively ( $p<0.05$ ).

Conclusion: The study showed that elective myocardial revascularisation in patients with severe left ventricular dysfunction and signs of myocardial viability is not necessarily associated with high operative mortality. It can be performed safely with respectable midterm survival in concordance with left ventricular function improvement, symptom relief and quality of life improvement.
\end{abstract}

\section{INTRODUCTION}

The results of the medical treatment of patients with coronary artery disease (CAD) and severe left ventricular (LV) dysfunction are poor. However, as many earlier and current studies demonstrate coronary artery bypass graft (CABG) procedure have improved long term survival in patients with impaired ventricular function ${ }^{1-6}$ over the last fifteen years. The benefit is most obvious in patients with severe LV dysfunction with ejection fraction (EF) less then $35 \%^{1}$ and signs of myocardial viability. The amount of viable myocardium dictates the degree of improvement in left ventricular function after revascularization ${ }^{2}$. Left ventricular function is an important predictor of early postoperative and late morbidity and mortality ${ }^{4}$. Despite improvement in surgical techniques, myocardial protection and postoperative care, the surgical risk remains high $^{3-5,9}$ and the procedure is still a major surgical challenge. There are however few options for alternative treatment. Transmyocardial laser revascularisation and dynamic cardiomyoplasty are limited in use and in indications. Heart transplantation is a terminal one considering the impossibility of revascularisation and its dependence on donor heart availability as well.

This retrospective study evaluates early postoperative (30-day after surgery) and midterm (1 year after surgery) results in 97 consecutive patients who underwent elective CABG for isolated ischemic heart disease with left ventricular EF $25 \%$ and lower. Early postoperative mortality, complications, clinical status difference were analyzed as early postoperative results (30-day after surgery), followed by analysis of midterm results figured in as 1-year mortality, EF difference and clinical status difference.

\section{MATERIALS AND METHODS}

Between September 1998 and December 2001, 97 consecutive patients whose preoperative EF (by planimetry) was less than or equal to $25 \%$ underwent elective CABG. Patients undergoing combined procedures as CABG with valvular surgery, left ventricular aneurysm resection or any other cardiac or aortic surgery, surgery for arrhythmia, angioplasty or thrombolytic therapy were excluded 
from the study. Patients undergoing urgent surgery due to acute evolving myocardial infarction were also excluded.

Preoperative clinical, echocardiographic and angiographic data are summarized in Table 1-5. Mean age at operation was 66 years ranging from 47 to 86 years. Fifteen $(15.5 \%)$ were women. Hypertension was present in $76(78.3 \%)$ patients, diabetes in 30 (30.9\%), obesity in 34 (35\%) patients. Preoperative and postoperative angina and dyspnoea were assessed according to the Canadian Cardiovascular Society (CCS) and to the New York Heart Association (NYHA) classification.

All 97 patients (100\%) had severe CCS angina and /or NYHA symptoms preoperatively. Seventy-eight (80\%) patients had dominating symptoms of angina class III-IV CCS, while 19 (20\%) patients had dominating symptoms class III-IV of NYHA functional classification. Mean class of CCS angina or NYHA dyspnoea were 3.1 or 2.6 respectively. Ninety-one ( $94 \%$ ) patients had a previous history of one or more myocardial infarctions. Preoperative ECHO showed a mean left ventricular EF $23.1 \%$ (16 \%-25\%). Cardiac cathetrisation was carried out in all patients preoperatively. Preoperative planimetry showed a mean EF $22 \%$ (range $18 \%-25 \%$ ). Mean end diastolic pressure of left ventricle (LVEDP) was $24 \mathrm{~mm} \mathrm{Hg}$ (9-54), mean end diastolic diameter of left ventricle (LVEDd) was $63 \mathrm{~mm}$ (53-67) preoperatively. Preoperative cardiac index (CI) was measured by Swan-Ganz thermodilution catheter in $56(58 \%)$ patients (Table 6). Major indications for surgery were dominating angina in 78 (80\%) patients, dyspnoea in 11 (11\%) patients.

Angiograms showed triple vessel disease in 77 (80\%) patients, severe LM disease in 18 (19\%) patients. Preoperative myocardial viability studies were assessed by stress thallium scintigraphy viability test of the myocardium in $40(41.2 \%)$ patients. Stress dobutamine echocardiography was assessed in 45 (46\%) patients.

Intra aortic balloon pump (IABP) insertion was required in none $(0 \%)$ patients preoperatively. IABP was inserted in 2 (2\%) patients intraoperatively before being weaned off CPB.

Follow up was completed for all 93 (100\%) patients surviving early postoperative period. Information was obtained from the patient interview and examination or by phone calls to the cardiologist or physicians. Postoperative follow-up included clinical assessment and transthoracic echocardiography. Angiography was not performed routinely during follow up.

\section{TECHNIQUE}

Ninety (93\%) procedures were performed using CPB and hypothermia of $32^{\circ}$ Centigrade. Roller pump and membrane oxygenators were used in all of these procedures. Seven procedures ( 7 \%) were off pump coronary artery bypass graft (OPCAB).

Distal anastomoses were performed during cross clamp time and aortic anastomoses were carried out using tangential aortic clamping with empty fibrillating
Table 1. Preoperative clinical data.

\begin{tabular}{|l|c|c|}
\hline Preoperative clinical data & $\mathrm{N}$ & $\%$ \\
\hline Women & 15 & 15.5 \\
\hline Men & 83 & 85.5 \\
\hline Hypertension & 76 & 78.3 \\
\hline Previous MI & 91 & 93.8 \\
\hline Diabetes mellitus & 30 & 30.9 \\
\hline Obesity & 34 & 35.0 \\
\hline Kreatinine $>170 \mu \mathrm{mol} / 1$ & 12 & 12.4 \\
\hline
\end{tabular}

Table 2. Preoperative clinical data.

\begin{tabular}{|l|c|c|}
\hline $\mathrm{n}=97$ patients & Class CCS & NYHA \\
\hline Mean dyspnoea & & 2.6 \\
\hline Mean angina & 3.1 & \\
\hline
\end{tabular}

Table 3. Preoperative angiographic data.

\begin{tabular}{|l|c|c|}
\hline Vessel disease & N & $\%$ \\
\hline Left main coronary artery disease & 18 & 18.6 \\
\hline Triple vessel disease & 77 & 79.4 \\
\hline
\end{tabular}

Table 5. Preoperative variables of left ventricle.

\begin{tabular}{|c|c|}
\hline Mean LVEDP & $24 \mathrm{~mm} \mathrm{Hg}$ \\
\hline Mean LVEDd & $63 \mathrm{~mm}$ \\
\hline
\end{tabular}

Table 6. Preoperative cardiac index $(\mathrm{N}=50)$.

\begin{tabular}{|c|c|c|}
\hline Cardiac index $(\mathrm{N}=56)$ & $\mathrm{N}$ & $\%$ \\
\hline $2.0-2.5$ & 8 & 14 \\
\hline $1.5-2.0$ & 38 & 76 \\
\hline$<1.5$ & 10 & 10 \\
\hline
\end{tabular}

or beating heart. Total number of grafts was 334. Mean number of grafts per patient was 3.4 (2-5). Left internal mammary artery (LIMA) graft was used in 90 (93\%) procedures.

Cold crystalloid cardioplegia (St. Thomas solution) was used in 50 (56 \%) procedures. Cold blood cardioplegia was used in 40 (44\%) procedures. The method of cardioplegia insertion was antegrade and intermittent (into grafts being already constructed). Mean CPB time 
was 68 min (40-89), mean cross clamp time was 36 min (18-50).

Peroperative or postoperative myocardial infarction was defined as the appearance of a new $\mathrm{Q}$ wave with an elevation of the Troponin I isoenzyme higher than $1.5 \mu \mathrm{kat} / 1$.

\section{DATA ANALYSIS}

Statistical analysis was performed using a paired t-test. A p-value less then 0.05 was considered significant.

\section{RESULTS}

\section{Early postoperative results}

Early postoperative (30 days) mortality was 4 (4.1\%) patients. Postoperative complications occurred in 50 (51.5\%) patients. The most common postoperative complications were atrial fibrillation in $35(36.1 \%)$ patients. The postoperative complications are summarized in Table 7. Mean duration of endotracheal intubation was 6.6 hours (3-20), mean duration of postoperative hospital

Table 7. Early postoperative complications.

\begin{tabular}{|l|c|c|}
\hline Complication & $\mathrm{N}$ & $\%$ \\
\hline Low cardiac output & 4 & 4.1 \\
\hline Atrial fibrillation & 35 & 36.1 \\
\hline Ventricular fibrillation & 5 & 5.1 \\
\hline Septicaemia & 4 & 4.1 \\
\hline Renal failure with need of CVVH & 8 & 8.2 \\
\hline Intraoperative MI & 2 & 2.1 \\
\hline Neurological complications & 2 & 2.1 \\
\hline
\end{tabular}

stay was 10 days (7-22). Eighty-three (89.2\%) patients were discharged without angina and also without severe dyspnoea class III-IV NYHA at home.

\section{Midterm results}

Mean follow up was 13 (12-16) months. No patient was lost to follow up. One year survival rate was $95.6 \%$ (89 patients). Four patients $(4.3 \%)$ died. The cause of death was heart failure several months after surgery in 2 cases (50\%), cerebral stroke in 1 case (25\%) and unknown cause of death also in 1 case $(25 \%)$. Transthoracic echocardiography was performed in 89 (100\%) of surviving patients one year after surgery. Left ventricular EF measured by echocardiography improved from $23.1 \%$ preoperatively to $36 \%$ one year after surgery (Fig. 1). Mean CCS class of angina of all survivors was 1.6 and mean class of NYHA was $1.7 . \quad 43(48.3 \%)$ patients were angina free, 17 (18.2\%) patients had symptoms of class III CCS

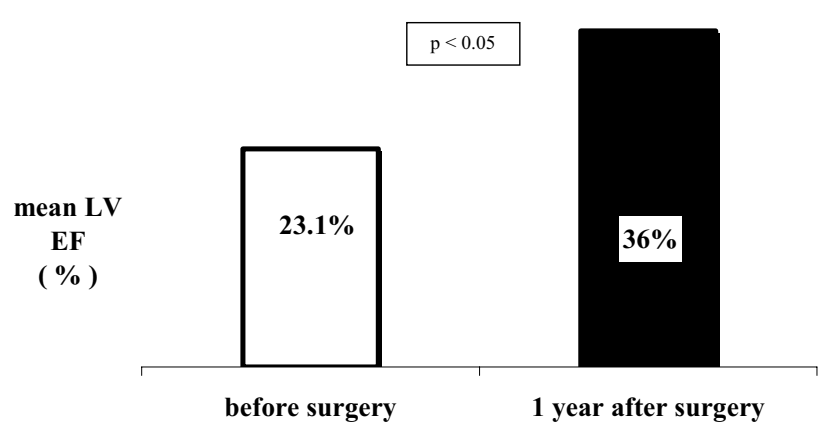

Fig. 1. Ejection fraction improvement.

and/or NYHA. None ( $0 \%$ ) of surviving patients had class IV symptoms of angina/dyspnoea CCS/NYHA.

\section{DISCUSSION}

A number of studies have concluded that CABG in patients with left ventricular dysfunction provide better prognosis than conservative treatment (1.3-5). Alderman et al. ${ }^{4}$ reported a 5 years survival rate of $43 \%$ for the medical group compared to $63 \%$ for the surgical group. The criteria determining impaired ventricular function are different.

The predictive value of viability assessment with quantitative positron emission tomography for symptomatic and functional outcome for coronary artery surgery as treatment for ischemic heart failure has been shown by Pagano $^{2}$.

Results supporting the use of CABG in patients with severe left ventricular dysfunction without case selection on the basis of viability studies or visibility of distal vessels has been reported by Mickleborough ${ }^{6}$. Nevertheless the degree of improvement in left ventricular function after revascularisation is dictated by the amount of viable myocardium ${ }^{2,8}$.

The limitations of the study are the fact that preoperative stress-thallium scintigraphy data were obtained in only $40(41.2 \%)$ patients. Stress dobutamine echocardiography was assessed in only 45 (46\%) patients. We used left ventricular ejection fraction assessed by echocardiography, ventriculography and CI in some patients to gain left ventricular function preoperatively. No control angiograms and ventriculography were performed in our patients during follow up as long as there was indication for it (sign of myocardial ischemia).

Echocardiography was used to assess ejection fraction postoperatively. A distinct LVEF improvement was showed comparing those two variables (preoperative and postoperative) assessed by ECHO.

The operative mortality rate in patients undergoing CABG is associated with several risk factors as female gender, advanced age, obesity, severity of coronary artery disease, low cardiac index, preoperative cardiac failure etc $^{5,7,11}$.

Less invasive cardiac surgical procedures are gaining increased interest among the surgical community. Multi- 
vessel off-pump coronary artery bypass (OPCAB) surgery has been made possible by the development of innovating techniques and various stabilisation systems). OPCAB operations has been demonstrated by several authors to reduce postoperative morbidity and mortality in high-risk patients $^{9-11}$. We performed 7 (7\%) of our operations using OPCAB technique, finding it less comfortable when manipulating the heart.

The previous study comparing techniques of cardiac arrest of Brat et al. approves that cold blood cardioplegia causes less myocardial damage when compared with cold crystalloid cardioplegia ${ }^{12,13}$. Similarly early functional restoration of myocardium accelerates by using cold blood cardioplegia ${ }^{13}$. We used both of these two techniques of cardiac arrest almost equally for.

Our findings are consistent with the concept that preoperative angina predicts good results, but its absence is not associated with poor results. An operative mortality of $4 \%$ and medium term survival in our group of patients showed that surgery could be performed safely with very good symptomatic relief. Quality of life improvement confirmed objectively with ejection fraction improvement were of clinical relevance (e.g. relief of angina and absence of heart failure symptoms).

Our findings suggest that $\mathrm{CABG}$ in patients with poor left ventricular function is indicated not only when angina is the predominant symptom. Its absence however is not necessarily associated with poor results ${ }^{6}$.

\section{CONCLUSION}

Given that myocardial revascularisation in patients with severe ischemic left ventricular dysfunction is associated with higher operative risk the analysis of early postoperative results showed the operative risk in such group of patients undergoing elective surgery is not necessarily associated with high mortality. Early postoperative morbidity was certainly high, but just ten patients suffered from such serious complications as severe renal dysfunction with the necessity for haemodialysis, ventricular arrhythmia, septicaemia, low cardiac output (LCO), intraoperative myocardial infarction so far. The midterm results (mortality, ejection fraction improvement and clinical status improvement) are also very encouraging. They strongly support safe surgical procedures with good symptomatic relief and an excellent midterm survival.

\section{REFERENCES}

1. Pigott JD, Kouchoukos NT, Oberman A, Cutter GR. (1985) Late results of surgical and medical therapy for patients with coronary artery disease and depressed left ventricular function, J Am Coll Cardiol 5, 1036-1045.

2. Pagano D, Townend JN, Littler WA, Horton R. (1998) Coronary artery bypass surgery as treatment for ischemic heart failure: The predictive value of viability assessment with quantitative positron emission tomography for symptomatic and functional outcome. JThoracic Cardiovasc Sur 115, 791-799.

3. Zubiate P, Kay JH, Mendez AM. (1977) Myocardial revascularization for the patient with drastic impairment of function of left ventricle. J Thor Cardiovasc Sur 73, 84-6.

4. Alderman EL, Fisher LD, Litwin P, Kaiser GC, Myers WO, Levine F. (1983) Results of coronary artery surgery in patient with poor left ventricular function (CASS). Circulation 68, 785-795.

5. Bouchart F, Tabley A, Litzler P.Y, Haas Hubscher C, Bessou JP, Soyer R. (2001) Myocardial revascularisation in patient with severe ischemic left ventricular dysfunction. Eur J Cardiothoracic Surg 20, 1157-1162.

6. Mickleborough LL, Carson S, Tamariz M. (2000) Results of revascularisation in patients with severe left ventricular dysfunction. J Thoracic Cardiovasc Sur 119, 550-557.

7. Milano CA, Whitw WD, Smith LR, Jones RH, Smith PK. (1993) Coronary artery bypass in patient with severely depressed ventricular function. Annals Thorac Surg. 56, 487-493.

8. Vanoverchelde JLJ, Gerber BL, D’Hondt AM, De Kock M. (1995) Preoperative selection of patients with severely impaired left ventricular function for coronary revascularisation Circulation 92 (Suppl. II), 37-44.

9. Arom KV, Flavin TF, Emery RW, Kshettry VR, Petersen RJ (1995) Is low ejection fraction safe for off-pump coronary bypass operation? Annals Thorac Surg 70, 1021-1025.

10. Eryilmaz S, Corapcioglu T, Eren TN, Yazicioglu 1, Kaya K, Akalin H. (2002) Off-pump coronary artery bypass surgery in left ventricular dysfunction. Eur J Cardiothoracic Surg. 21, 36-40.

11. Meharwal ZS, Trehan N. (2002) Off-pump coronary artery bypass grafting in patients with left ventricular dysfunction. Heart Surg Forum. 5, 41-45.

12. Brát R, Tošovský J, Januška J. (1997) Blood cardioplegia in patients with impaired left ventricular function. Cardiol 7, 15-17.

13. Brát R, Tošovský J, Januška J, et al. (2000) Comparison between blood and crystalloid cardioplegia in patients with left ventricular dysfunction undergoing coronary surgery. Acta Medica 43, 107110 . 